лы международной конференции. СПб.: Эрмитаж, 2014. С. 254-258.

5. Васильев И.Б., Овчинникова Н.В. Энеолит // История Самарского Поволжья с древнейших времен до наших дней. Каменный век. Самара: Изд-во СНЦ PAH, 2000. $310 \mathrm{c}$.

6. Агапов С.А., Васильев И.Б., Пестрикова В.И. Хвалынский энеолитический могильник. Саратов: Изд-во Саратовского гос. ун-та, 1990. 160 с.

7. Моргунова Н.Л. Ивановская стоянка эпохи неолита-энеолита в Оренбургской области // Энеолит Восточной Европы. Куйбышев, Изд-во КГПИ, 1980. C. 104-124.

8. Матюшин Г.Н.Энеолит Южного Урала. М.: Наука, 1982. 328 с.

9. Антипина Е.Е. Археозоологические исследования: задачи, потенциальные возможности и реальные результаты // Новые археозоологические исследования в России, Москва: Изд-во Языки славянской культуры. 2003. С. 7-34.
10. Лебедев В.Д. Пресноводная четвертичная ихтиофауна Европейской части СССР. М.: Изд-во МГУ, 1960. 404 c.

11. Мовчан Ю.В. Риби України. К.: Изд-во Золоті ворота, $2011.420 \mathrm{c}$.

12. Bradley R. The Moon and the Bonfire. An investigation of three stone circles in northeast Scotland. Edinburgh: Society of Antiquaries of Scotland. 2005. 124 p.

13. Яниш Е.Ю., Антипина Е.Е. Промысловые рыбы древней Ольвии (I-III вВ. н.э.) и ее окрестностей // Зоологический журнал, 2013, Т. 92, № 9. С. 11901200.

14. Никольский Г.В. О биологической специфике фаунистических комплексов и значении их для зоогеографии // Очерки по общим вопросам ихтиологии. М.: Л.: Изд-во АН СССР, 1953. С. 65-67.

Работа выполнена при финансовой поддержке Министерства образования и науки РФ (госзадание $33.1195 .2014 / \kappa)$.

\title{
FISHERY IN THE ENEOLITHIC FOREST-STEPPE OF THE VOLGA REGION (ON EXCAVATION MATERIALS OF LEBYAZHINKA VI SETTLEMENT IN 2013-2014 YEARS)
} (C) 2016

\author{
A.I. Korolev, candidate of history sciences, dean of History Faculty, \\ associate professor of Domestic History and Archaeology Department \\ A.A. Shalapinin, candidate of history sciences, researcher of Scientific Department \\ Samara State University of Social Sciences and Education, Samara (Russia) \\ E.Y. Yanish, candidate of biological sciences, junior researcher of Animal Monitoring and Conservation Department \\ I.I. Schmalhausen Institute of Zoology, Kiev (Ukraine)
}

\begin{abstract}
The following paper contains information about fishers' weapons and fish bones founded in Lebyazhinka VI eneolitic settlement in the forrest-steppe region of the Volga river. We analyse materials of the second half of the IV millennium BC. The filling of pits represents dwellings with the «inner edge», stone and bone tools, animal bones of turtles, birds and fish. The importance of this studiing is in the possibility of a complex view. The purpose of this article is to analyze the fish catching, hunting and fish bones. Hunting tools are represented by bone harpoons with one, two or many teeth, arranged on one side. There are two types of fishbone hooks: whole and composite. We determined the typological features of catching tools, and moreover we determined quantitative, species, age and size characteristics of fish. The main fishes were pike and catfish, then luce, pike, perch, roach, sturgeon, sterlet. The fish sizes are medium and large, the age is about 8-10 years. We have an opinion of the way of fishing including hooks, harpoons, nets and stakes. The research will be completed with new materials.

Keywords: forrest-steppe region; late eneolite; archezoology; complex study; Lebyazhinka VI; eneolithic settlement; dwellings with the «inner edge»; bone hook-lure; composite hook; harpoon; fishing; pike and catfish; luce; pike; perch; roach; sturgeon; sterlet.
\end{abstract}

УДК 902.903 .023

\section{КРУПНОТАРНЫЕ СОСУДЫ БРОНЗОВОГО ВЕКА ТУРГАНИКСКОГО ПОСЕЛЕНИЯ В ОРЕНБУРГСКОЙ ОБЛАСТИ}

(C) 2016

Н.П. Салугина, кандидат исторических наук, доцент кафедры теории и истории культуры Самарский государственный институт культуры, Самара (Россия)

Н.Л. Моргунова, доктор исторических наук, профессор, заведующий археологической лабораторией Оренбургский государственный педагогический университет, Оренбург (Россия)

М.А. Турецкий, кандидат исторических наук, старший научный сотрудник

Поволжский филиал Института российской истории РАН, Самара (Россия)

Аннотация. В керамической коллекции Турганикского поселения в Оренбургской области выделяется группа керамики эпохи бронзы, которая по своим морфологическим и технологическим показателям резко выделяется из основной группы посуды. Это сосуды крупных размеров с массивными венчиками и раздутым туловом. Авторы условно назвали эти сосуды хумами. Задачей данного исследования является попытка определить культурно-хронологическую позицию указанной группы посуды в системе древностей раннего - среднего бронзового века. Внутри этой группы авторы выделяют два типа. Основанием для выделения типов послужили 
особенности оформления верхней части сосудов. К первому типу отнесена керамика с Турганикского поселения и сосуд из курганного могильника Переволоцкий I. Морфологические и технологические особенности, а также серия радиоуглеродных дат позволили отнести эти сосуды ко времени начала формирования ямной культуры в Волго-Уральском регионе (репинский этап). Авторы предполагают, что появление здесь подобных сосудов является подражанием майкопскому гончарству. Это могло быть проникновение малых групп мастеров или активизация контактов с предкавказским населением. Второй тип керамики с Турганикского поселения находит аналогии в курганном могильнике Кардаиловский I (курган 1, погребение 3) в Оренбургской области, в Северном Прикаспии, бассейне р. Самары, Прикубанье и в Поднепровье. Исследователи отмечают немногочисленность и оригинальность данной посуды. Хронологическая и культурная позиция таких сосудов определяется в пределах III тыс. до н.э. (в калиброванных значениях).

Ключевые слова: ранний и средний бронзовый век; керамика типа хумов; реповидные сосуды; радиоуглеродная хронология; культурная принадлежность; ямная; майкопско-новосвободненская; катакомная культуры; орнамент; технология изготовления керамики; исходное сырье; формовочные массы; глина; илистая глина; шамот; дробленая раковина.

Исследования Турганикского поселения на реке Ток в западной части Оренбургской области начались в начале $80-$ х годов ХХ в. [1, с. 58-78]. В 20142015 гг. с целью выяснения культурной и хронологической принадлежности материалов бронзового века, происходивших из верхнего культурного слоя, раскопки поселения были продолжены. Керамика из этого слоя предположительно была отнесена к РБВ и, таким образом, по хронологии и в культурном плане она была синхронизирована и связана с ранним (репинским) горизонтом ямной культуры, что позволили сделать первые ${ }^{14} \mathrm{C}$ даты, полученные по фрагментам керамики [2, с. 25 , табл. 9; 3, с. 181]. Новые ${ }^{14} \mathrm{C}$ даты, полученные по костям животных, подтвердили это заключение [4, с. 119].

Керамика бронзового века характеризуется толстостенностью и визуально хорошо заметными включениями раковины $[5$, с. 121]. Всего найдено немногим более 2000 фрагментов керамики эпохи бронзы. По способу обработки поверхностей она подразделяется на 2 группы. Для первой, более многочисленной, типичным признаком является заглаживание внешней и внутренней поверхностей сосудов с помощью крупнозубчатых гребенчатых штампов в виде расчесов в разных направлениях - в «паркетном» стиле. Посуда представлена горшковидными и баночными формами, орнаментированными веревочкой, гребенчатыми штампами, ямочными вдавлениями, значительная часть ее не орнаментирована. Поскольку в коллекции отсутствуют плоские днища, видимо, посуда была круглодонной. Найдено одно круглое днище с крупными расчесами. Технологический анализ, проведенный по методике А.А. Бобринского [6], показал разнообразие в навыках отбора исходного сырья и составления формовочных масс. Большинство неорнаментированной посуды с расчесами изготовлено из глины разной степени запесоченности, к которой добавлялась либо дробленая раковина и органический раствор, либо шамот, дробленая раковина и органический раствор. Вторая группа представлена сосудами со слегка бугристыми поверхностями, без расчесов. Форма сосудов: слабо профилированная горшковидная или баночная [7, с. 60-70].

В первой группе выделяются крупные толстостенные горшки типа хумов с сильно отогнутыми и утолщенными венчиками. Внутренние поверхности сосудов и срезы венчиков заглажены крупнозубчатым гребенчатым штампом. Поскольку полная реконструкция сосудов невозможна, то судить об обработке внешней поверхности затруднительно. Однако, судя по найденным совместно с венчиками большим количеством стенок сосудов, заглаженных с обеих сторон крупнозубчатым штампом, можно предполагать, что внешняя поверхность также обрабатывалась аналогично.

В данной статье особое внимание уделено именно этой группе сосудов. Внутри указанной группы посуды выделяется два типа по особенностям оформления венчиков: 1) срез венчика плоский или слегка округлый, иногда немного скошен внутрь, с внутренней стороны наблюдается плавная линия перехода от венчика к тулову. При переходе от венчика к тулову сформирована невысокая (до 4 мм) шейка, примерный диаметр горловины сосудов по внешнему краю венчиков - от 22 до $30 \mathrm{~cm}$, ширина плоской поверхности венчиков 2,5-3 см. Керамика не орнаментирована (рис. 1, 1-3); 2) срез венчика довольно резко скошен внутрь, иногда образуя своеобразный выступ - уступ, после чего венчик плавно переходит в тулово. По плоскости венчика и, видимо, по плечикам был нанесен орнамент из разреженных рядов крупных треугольных наколов (рис. 2, 2). Диаметр горловины 19 см, ширина верхней части венчика 4 см.

Керамика первого типа представлена 12 фрагментами от 4-х сосудов. Все они обнаружены на участках 5, 6 и 9 на уровне 9-10 штыков, т.е. в верхнем культурном слое поселения совместно с основной массой керамики 1 группы. Сосуды изготовлены только из запесоченной глины. Формовочная масса составлена по одному рецепту: дробленая, предварительно нагретая раковина + органический раствор [7, с. 70]. Таким образом, хумы 1 типа на Турганикском поселении, с одной стороны, отличаясь от керамики с расчесами по форме, близки части этой керамики по технологии изготовления. О культурном и, вероятно, хронологическом единстве этой посуды с группой керамики с расчесами свидетельствуют и такие признаки, как способ обработки поверхности, видимо, круглодонность и, прежде всего, радиоуглеродные даты, полученные для слоя с керамикой с расчесами. Важно отметить факт, что единственное круглое днище с расчесами изготовлено в соответствии с емкостно-донной программой конструирования начинов, что характерно для погребальной посуды ямной культуры репинского этапа $[8$, с. 90$]$. В свое время А.А. Бобринский отмечал, что данный прием конструирования наиболее распространен на Северном Кавказе и в Закавказье, в частности, он отмечен по материалам двух археологических культур: куро-аракской и майкопской $[6$, c. 115-116]. 

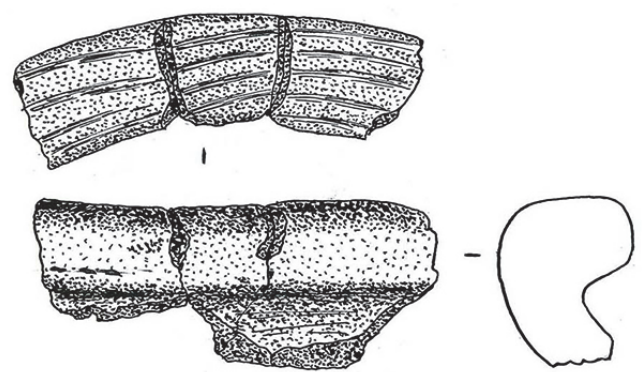

1

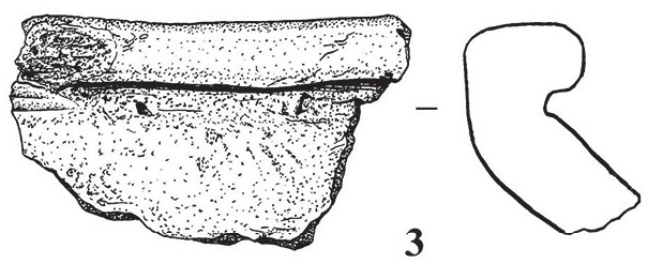

3

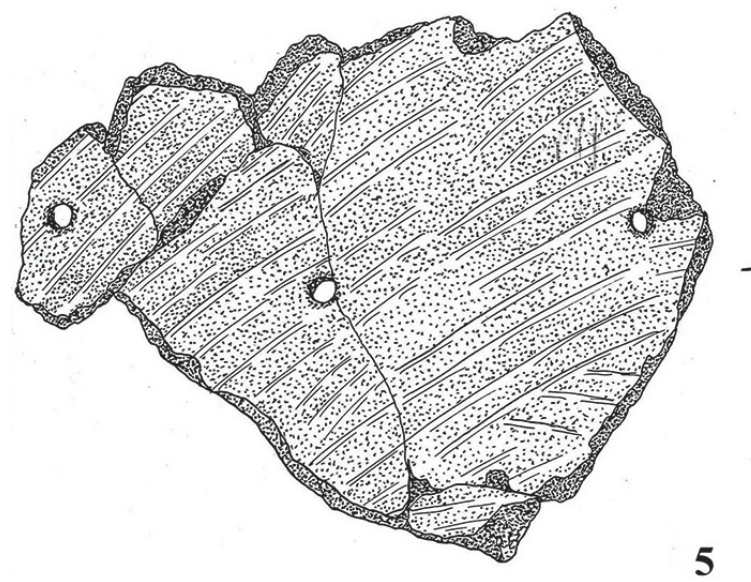

Рисунок 1 - Керамика. Хумы 1 типа: 1-3 - Турганикское поселение;

4-6 - Переволоцкий I кург. мог., кург. 7, погр. 2
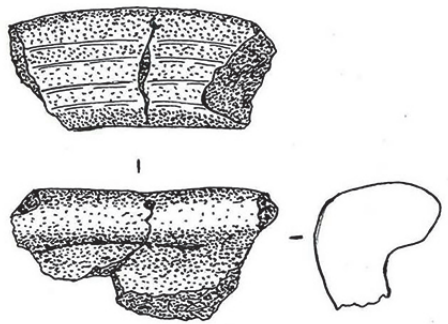

2
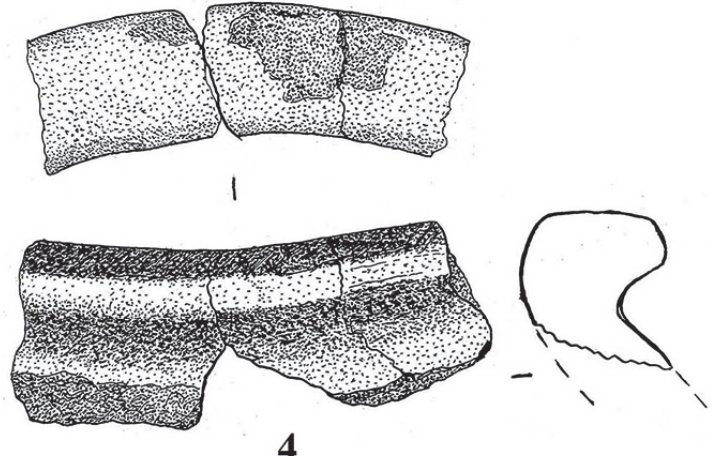

4
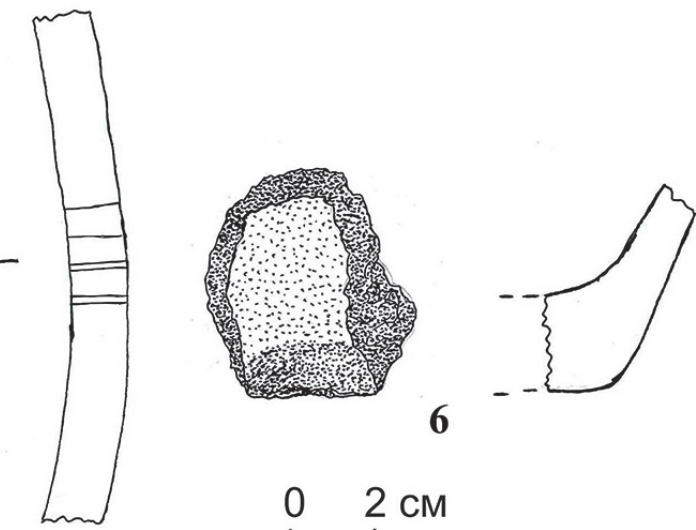

6

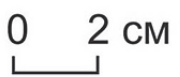

Учитывая малочисленность данной посуды на фоне общей массы гончарных изделий РБВ на Турганикском поселении, а также ее отличительные особенности, можно предположить, что хумы изготавливались по особой технологии и имели специальное хозяйственное назначение.

Аналогичный по форме сосуд обнаружен в погребении 2 кургана 7 Переволоцкого курганного могильника, относящегося к ямной культуре [9, с. 49-51]. Он имеет массивный, отогнутый наружу венчик и раздутое тулово, по всем поверхностям покрыт расчесами крупного гребенчатого штампа (рис. 1, 4-6). Сосуд отличается от турганикских хумов наличием уплощенного дна и технологией изготовления. Мастерами отбиралась ожелезненная, незапесоченная глина, в состав формовочной массы вводился крупный шамот и органический раствор, возможно, в виде выжимки из навоза. Начин изготовлен в соответствии с донноемкостной программой, возможно применение формы-модели. Полое тело конструировалось из крупных лоскутов, наращиваемых по спиралевидной траектории. Обе поверхности сосуда заглажены крупным гребенчатым штампом, оставляющим на поверхности расчесы в разных направлениях.
Впервые к интерпретации известного на тот момент единственного венчика сосуда из раскопок Турганикского поселения в 1982 г. обратился С.В. Богданов. Он попытался реконструировать его форму как корчагу и отнес ее к «одной из линий развития майкопско-новосвободненской керамики позднего периода» $[10$, с. 170$]$. Автор, на наш взгляд, не достаточно корректно провел реконструкцию сосуда как корчагу с плоским дном, поскольку достоверно связать с венчиком стенки и дно было невозможно. По его мнению, этот сосуд отражает глубокие контакты носителей ямной культуры Волго-Уральских степей и майкопско-новосвободненской культуры... [10, с. 171]. Полученные нами в ходе последних раскопок материалы и сопоставление их с керамикой майкопской культуры [11, с. 22-41, рис. 44-65] не позволяет согласиться с весьма категоричным выводом С.В. Богданова о единой для них генетической линии развития, так как майкопские сосуды, хотя по размерам и отчасти по форме близки турганикским хумам, но совершенно оригинальны в сравнении с последними (техника конструирования с применением гончарного круга, отогнутые без утолщения венчики и др.). Однако заключение автора о возможности синхронного развития обеих традиций подтверждается. 
Прежде всего, следует обратиться к радиоуглеродным датам, серийно полученным нами в последнее время как по керамике 1 группы с расчесами, так и по костям животных из слоя РБВ.

Серия радиоуглеродных определений по костям животных из верхнего культурного слоя (шт. 8-10) подтвердила ранее известную дату по керамике с расчесами Турганикского поселения - Кі $155974710 \pm 80$ ВР [3, с. 181]. В целом, для слоя БВ устанавливается интервал от 3700 до 3400 лет ВС, что соответствует известным датам по керамике поселений Кызыл-Хак I и II [2, с. 25], а также других памятников раннеямного (репинского) горизонта и радиокарбонным датам майкопской культуры раннего и среднего диапазона $[12$, с. $114-115 ; 4$, c. 119$]$.

Керамика второго типа в материалах Турганикского поселения представлена одним сосудом (рис. 2, 2). В качестве исходного сырья для его изготовления отбиралась незапесоченная илистая глина, в формовочную массу вводились не калиброванный шамот, дробленая, предварительно нагретая раковина и органический раствор.

Близкий по форме сосуд происходит из исследованного в 1977 году Н.Л. Моргуновой курганного могильника Кардаиловский I (курган 1, погребение 3). Он был обнаружен во фрагментированном состоянии, его многочисленные обломки встречались в засыпи могильной ямы многоступенчатой конструкции, захоронение в которой не найдено. Судя по сложности ритуала и крупным размерам самого кургана, кострищу на ступенях ямы и отсутствию следов ограбления, данный комплекс являлся сакральным комплексом.

Сосуд очень крупный, с массивным утолщенным венчиком и плоской поверхностью его края шириной 3,5 см. Внешний диаметр горловины 31 см (рис. 2, 1). Ниже венчика суженная невысокая шейка резко переходит в тулово под углом примерно в 45 градусов. В верхней части сосуда на плечиках имеется валик, украшенный с верхней и нижней стороны отпечатками крупнозубчатого штампа. Ниже и выше валика нанесены широкие волнистые линии тем же гребенчатым штампом. Вся поверхность сосуда, а также плоский верх венчика заглажены штампом, оставляющим на внутренней и внешней поверхностях расчесы в разных направлениях. Дно, возможно, было круглым, поскольку фрагменты плоского дна не найдены, несмотря на многочисленность обломков. Автор сочла возможным соотнести данный сосуд с сосудами реповидной формы катакомбной культуры $[13$, с. $12 ; 14$, c. 11-12, рис. 7]. Сравнение проводилось прежде всего с материалами Подонья [15, с. $82-87]$. Однако кардаиловский сосуд отличается от последних формой придонной части, не столь сильно раздутым туловом и отсутствием плоского широкого дна. Сосуд изготовлен из незапесоченной илистой глины, к которой при составлении формовочной массы добавлялись крупный шамот и органический раствор.

Керамика, подобная 2 типу хумов, в единичных экземплярах встречена на широкой территории: в Северном Прикаспии, бассейне р. Самары, Прикубанье и в Поднепровье. Исследователи отмечают необычность данной керамики и пытаются найти ей культурно-хронологическую позицию.
На территории Северного Прикаспия обнаружены два сосуда, близкие по форме изучаемым сосудам [16, c. 125]. Сосуд с поселения Тау-Тюбе орнаментирован в верхней части рядами вертикальных отпечатков ногтя, а ниже - наклонными расчесами. Дно сосуда не сохранилось, поэтому восстановить полную форму невозможно (рис. 2,4 ). Сосуд изготовлен из не запесоченной глины, к которой при составлении формовочной массы добавлен крупный шамот и органический раствор, возможно, в виде выжимки из навоза. В составе шамота фиксируется раковина. Сосуд из Досанга плоскодонный, украшенный волнистым налепным валиком, волнистыми и горизонтальными рядами наклонных отпечатков гребенчатого штампа. Орнаментальная композиция состоит из заштрихованных треугольников с бахромой, сплошных полос и горизонтальной елочки (рис. 2,3 ). По визуальному определению авторов, в изломе сосуда фиксировалась примесь «толченой раковины». Они считали, что форма данных сосудов сближает их с керамикой предкавказской катакомбной культуры, отмечая, при этом, что она изготовлена полтавкинским населением под определенным воздействием катакомбных племен $[16$, c. 117,127$]$.

В бассейне р. Самары подобные сосуды обнаружены в курганах 2 и 7 могильника Красносамарское IV. В кургане 2 развал сосуда найден во время снятия погребенной почвы, в 5,71 м к ЮЮЗ от центра кургана. Примерно восстановленный диаметр сосуда около $50 \mathrm{~cm}$, толщина стенок от 1,1 до $1,5 \mathrm{~cm}$. Внешняя и верхняя часть внутренней поверхности сосуда заглажена крупным гребенчатым штампом, отставляющем следы глубоких расчесов. Визуально авторы определили примесь раковины. Орнамент, нанесенный отпечатками перевитого шнура, располагался в верхней части сосуда. Внешняя сторона венчика украшена рядом вертикальных отпечатков. Под венчиком проходит двойной ряд горизонтальных прямых линий, от которых на тулово спускаются вытянутые треугольники, заполненные горизонтальными линиями, и направленные вершинами вниз. Основания треугольников примыкают к горизонтальным линиям (рис. 2, 6). В кургане 7 развал сосуда происходил из насыпи. Внешняя его поверхность заглажена крупным гребенчатым штампом, вероятно, тем же штампом нанесен орнамент в виде беспорядочно нанесенных вертикально-наклонных вдавлений. Для его изготовления отбиралась ожелезненная не запесоченная глина, в которой единично представлен окатанный мелкий песок и оолитовый бурый железняк. Формовочная масса составлена по рецепту: шамот крупный + дробленая раковина + органический раствор, возможно, в виде выжимки из навоза. Сосуд конструировался из коротких жгутов, наращиваемых по спиралевидной траектории, возможно применение формы - модели. Авторы исследования относят эти курганы к началу среднего бронзового века [17, с. 295].

К сожалению, ни прикаспийские, ни самарские памятники с находками керамики с утолщенными венчиками типа хумов не датированы радиоуглеродным методом, а по археологическим данным не имеют четкой хронологической привязки к тому или иному этапу ямной культуры. 

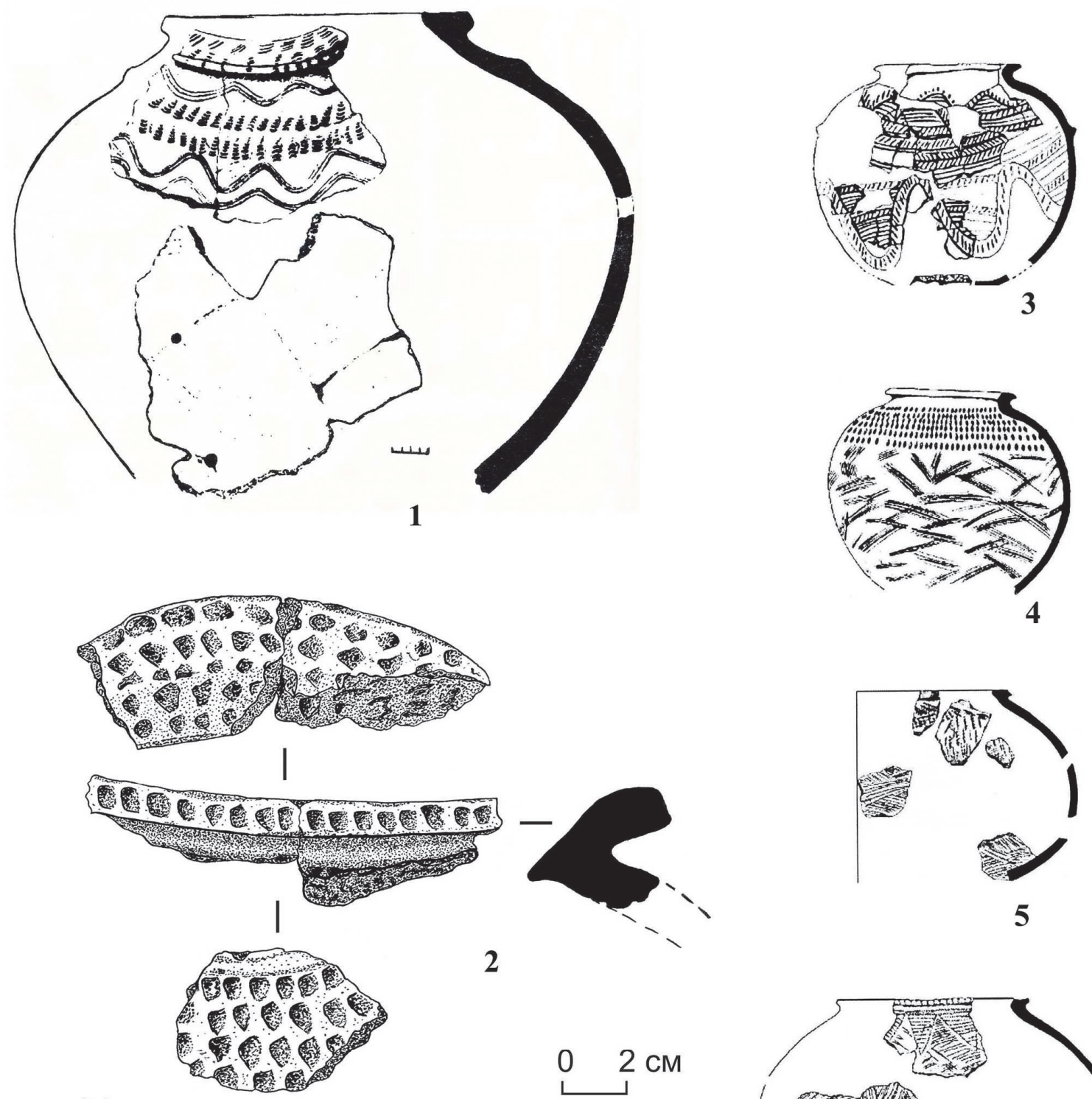

2
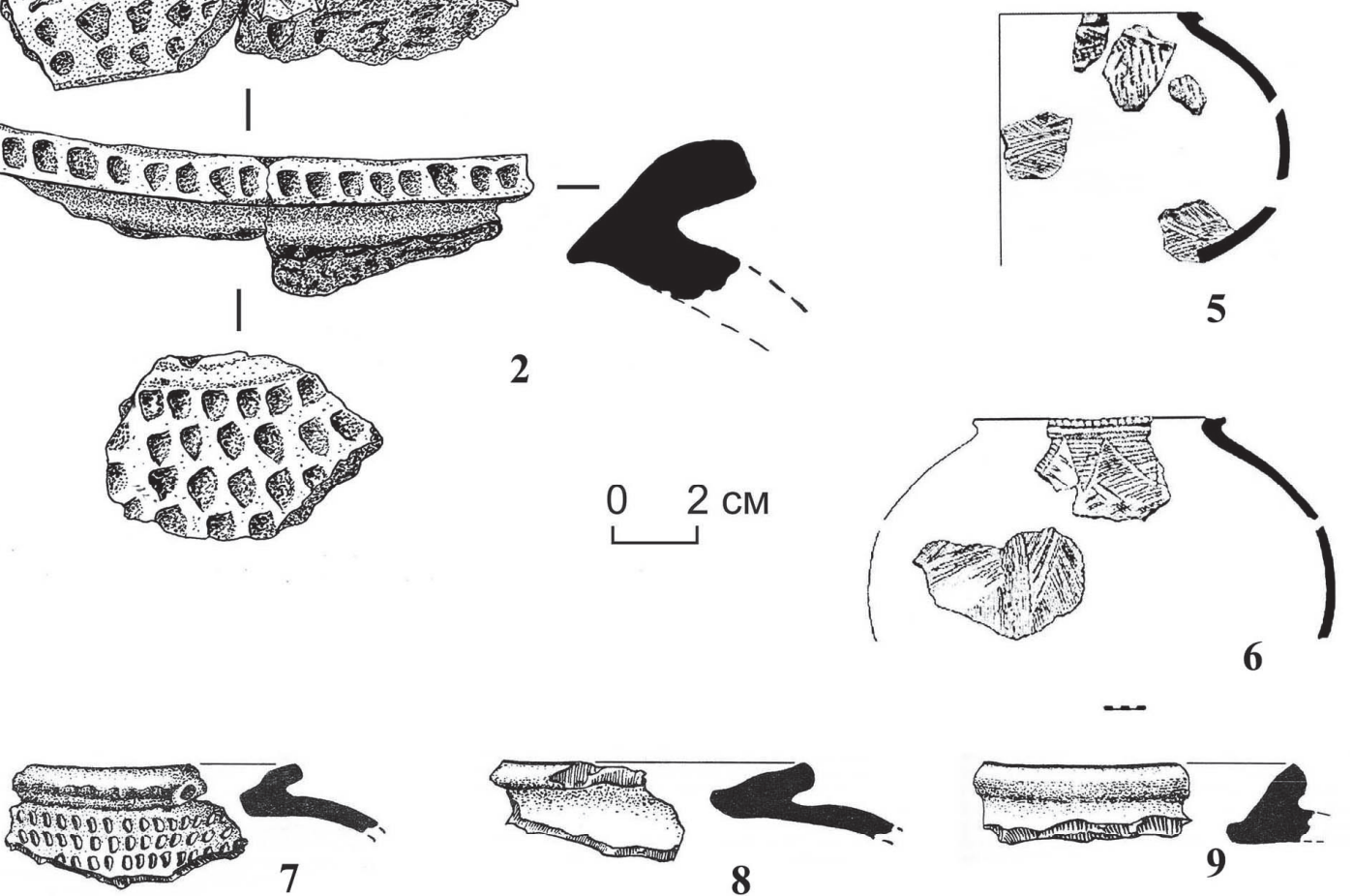

6

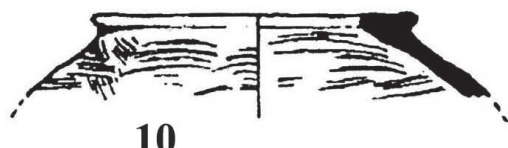

10

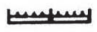

Рисунок 2 - Керамика. Хумы 2 типа и их аналогии. 1 - Кардаиловский I кург. мог., кург.1, погр. 3;

2 - Турганикское поселение; 3 - Досанг; 4 - Тау-Тюбе; 5 - Красносамарское IV кург. мог., кург. 7, насыпь; 6 - Красносамарское IV кург. мог., кург. 2, погребенная почва;

\section{7-9 - Михайловское поселение, верхний слой; 10 - Олений, кург. 3, насыпь}

Близкие сосуды зафиксированы в новотиторовской культуре Прикубанья. Исследователь данной культуры А.Н. Гей при анализе керамического материала выделяет особую группу 8, тип 8-2: крупные и очень крупные «тарные» сосуды с раздутым туловом и резким отгибом утолщенного или «манжетовидного» венчика [18, с. 144 ; рис. 44: 11-15]. В составе формовочной массы фиксируется примесь шамота и органика (определения И.А. Гей). Практически все сосуды покрыты крупными расчесами, чаще всего и 
снаружи, и внутри, орнаментация на них не отмечена. Определение их хронологической позиции очень проблематично. А.Н. Гей пишет, что сосуды этой группы найдены в могилах всех трех этапов новотиторовской культуры. Однако автор сам признает, что выделенные этапы достаточно условны.

И все же А.Н. Гей пытается определить культурнохронологическую позицию указанных сосудов. Он считает, что: 1) по форме тулова и устройству венчика эти сосуды могут быть сопоставимы с крупными тарными сосудами позднемайкопского или майкопсконовосвободненского круга; 2) характерная раздутость тулова и особенно форма горизонтально отогнутых утолщенных венчиков сближают тип 8-2 с классическими реповидными сосудами позднейших катакомбных памятников Предкавказья, что, с учетом бесспорного хронологического приоритета НТ культуры, позволяет присвоить новотиторовской таре наименование «протореп», видеть в ней прямые прототипы тарной посуды катакомбных племен.

На наш взгляд, в тип 8-2 отнесены очень разнообразные сосуды, и только один из них имеет отношение к рассматриваемой теме - сосуд из насыпи кургана 3 могильника Олений (рис. 2, 10) [18, с. 145, рис. 44: 13]. Учитывая все выше сказанное, сложно однозначно определить культурно-хронологическую позицию данного сосуда, вероятно, его можно датировать в рамках всей новотиторовской культуры [18, c. 198]. Однако хронология НТ культуры не обеспечена абсолютными датами и ее соотношение во времени с другими степными и предкавказскими культурами весьма проблематична. Важным в этой связи представляется тезис А.Н. Гея о ямном компоненте в сложении новотиторовской культуры, он даже выделяет ямно-новотиторовскую группу погребений [18, c. 198-200].

Следует отметить, что до появления новых материалов по Турганикскому поселению и Переволоцкому I курганному могильнику все приведенные выше аналогии рассматривались в работах О.Д. Мочалова и П.Ф. Кузнецова [19, с. 74-75; 17]. Сделав полную сводку крупных реповидных (тарных) сосудов и подробно остановившись на типе 8-2 новотиторовской керамики, авторы предположили, что в ее распространении важную роль сыграл прикубанский импульс в Заволжье и, соответственно, влияние традиций Прикубанья на территорию северо-востока Волго-Уралья [17, с. 293]. В то же время, авторы обращают внимание на ямный компонент в формировании новотиторовской культуры, что выражается в близости некоторых форм керамики новотиторовской культуры (І группа) с ямными сосудами. Они объясняют этот факт уже возможностью прямого взаимодействия указанных культурных групп. Далее, отмечая отсутствие монолитности черт материальной культуры в памятниках новотиторовской культуры, они сопоставляют этот факт уже с полтавкинской культурой [17, с. 294]. Обобщая свои наблюдения, авторы видят первичный источник появления крупных реповидных форм в северокавказском регионе. Из контекста статьи можно предполагать, что они относят рассматриваемую керамику к началу III тыс. до н.э., ко времени позднеямной и раннекатакомбной культур $[17$, с. 295$]$.
Аналогичные по форме и с подобной орнаментацией сосуды обнаружены в третьем слое Михайловского поселения (рис. 2, 7-9). Исследователи данного поселения относят третий слой к позднеямной культуре. Отмечая сходство данных сосудов с реповидными катакомбными, авторы все же отмечают их значительное различие и полагают, что они «могли предшествовать распространению подобного типа тарной посуды в Предкавказье в позднекатакомбное время [20, рис. XVI; 21, с. 72].

Сравнивая сосуды реповидной формы из погребений раннего бронзового века Поднепровья, Д.Л. Тесленко пришел к выводу о том, что подобные сосуды могли появиться в разных культурно-хронологических центрах, иначе придется ставить вопрос о сосуществовании, по крайней мере, в Правобережье Днепра, ямного и катакомбного населения [22, с. 45-47].

Все авторы, которые обращались к изучению крупной тарной посуды типа хумов, в основном имели дело с приземистыми, так называемыми сосудами «реповидной» формы с широким, значительно превышающим диаметр горловины, дном. Турганикские хумы существенно отличаются от реповидных сосудов из катакомбных памятников.

Исследователи сходятся во мнении, что истоки традиции производства реповидных сосудов в степях Восточной Европы восходят к культурам Северного Предкавказья. В хронологическом и культурном плане подобные находки чаще всего определяются в пределах III тыс. до н.э. (в калиброванных значениях) и соотносятся с новотиторовскими, катакомбными, позднеямными и ямно-катакомбными памятниками. В то же время, в каждом случае отмечаются какие-либо особенности в морфологии этих сосудов. Что касается сравнений в технологии их производства, то по данному параметру это сделать сложно из-за небольшого числа подобных исследований. Можно лишь отметить, что применялось незапесоченное сырье, в виде как природной, так и илистой глины. Обязательным компонентом формовочной массы был шамот и органический раствор, реже - дробленая, предварительно нагретая раковина.

Таким образом, анализ крупнотарной посуды Турганикского поселения склоняет к мысли о местном характере производства сосудов подобного типа и, видимо, об особенном хозяйственном предназначении этой посуды. Судя по типологии турганикских хумов 1-го типа и переволоцкого сосуда, с опорой на радиоуглеродные даты, данные материалы в отличие от реповидных сосудов (хумов 2-го типа) относятся к гораздо более раннему времени, к началу формирования ямной культуры в волго-уральском регионе на ее репинском этапе. Вполне возможно, что появление здесь данной традиции связано с подражанием майкопскому гончарству в связи с импульсом (проникновением малых групп мастеров) или с активизацией контактов с предкавказским населением в период, когда в Приуралье начинается становление местного металлургического центра на базе Каргалинского месторождения медной руды. В конце РБВ или в самом начале СБВ сосуды подобной формы продолжают производиться населением разных культурно-хронологических групп, что проявляется в особенностях форм и технологии изготовления. 


\section{СПИСОК ЛИТЕРАТУРЫ:}

1. Моргунова Н.Л. Турганикская стоянка и некоторые проблемы самарской культуры // Эпоха меди Восточной Европы. Куйбышев: Изд-во КГПИ, 1984. C. 58-78.

2. Моргунова Н.Л., Выборнов А.А., Ковалюх Н.Н., Скрипкин В.В. Хронологическое соотношение энеолитических культур волго-уральского региона в свете радиоуглеродного датирования // РА. № 4. 2010. C. $19-28$.

3. Моргунова Н.Л. Приуральская группа памятников в системе волжско-уральского варианта ямной культурно-исторической области. Оренбург: Изд-во ОГПУ, 2014. $348 \mathrm{c}$.

4. Моргунова Н.Л., Турецкий М.А., Кулькова М.А., Нестерова Л.А. Турганикское поселение в южном Приуралье: стратиграфия, планиграфия и радиоуглеродная хронология // Традиции и инновации в изучении древнейшей керамики: материалы международной научной конференции 24-27 мая 2016 г. СанктПетербург: ИИМК РАН, 2016. С. 116-120.

5. Моргунова Н.Л., Салугина Н.П. Культурная и хронологическая принадлежность керамики бронзового века Турганикского поселения в Оренбургской области // Традиции и инновации в изучении древнейшей керамики: материалы международной научной конференции 24-27 мая 2016 г. Санкт-Петербург: ИИМК РАН, 2016. С. 121-124.

6. Бобринский А.А. Гончарство Восточной Европы. Источники и методы изучения. М.: Наука, 1978. $272 \mathrm{c}$.

7. Салугина Н.П. Результаты технико-технологического анализа керамики репинского облика стоянки Турганик (предварительные итоги) // Археологические памятники Оренбуржья. Вып. 12. Оренбург: ООО ИПК «Университет», 2016. С. 60-70.

8. Салугина Н.П. Технология керамики репинского типа из погребений древнеямной культуры ВолгоУралья // РА. № 3. 2005. С. 85-92.

9. Моргунова Н.Л., Евгеньев А.А., Крюкова Е.А., Купцова Л.В., Харламов П.В., Файззулин И.А. Переволоцкий курганный могильник в Оренбургской области: предварительные результаты исследования // Археологические памятники Оренбуржья. Вып. 12. Оренбург: ООО ИПК «Университет», 2016. С. 21-51.

10. Богданов С.В. Эпоха меди степного Приуралья. Екатеринбург: УрО РАН, 2004. 285 с.

11. Кореневский С.Н. Древнейшие земледельцы и скотоводы Предкавказья. М.: Наука, 2004. 243 с.
12. Кореневский С.Н., Резепкин А.Д. Радиокарбонная хронология памятников круга майкопского кургана и новосвободненских гробниц // Проблемы истории, филологии, культуры. Вып. XXII. М.-Магнитогорск-Новосибирск, 2008. С. 109-127.

13. Моргунова Н.Л. К вопросу об общественном устройстве древнеямной культуры (по материалам степного Приуралья) // Древняя история населения Волго-Уральских степей. Оренбург: ОГПИ, 1992. C. $5-27$.

14. Моргунова Н.Л. Курганы у сел Краснохолм и Кардаилово в Илекском районе // Археологические памятники Оренбуржья. Оренбург: Печатный Дом «ДИМУР», 1996. С. 8-43.

15. Братченко С.Н. Нижнее Подонье в эпоху средней бронзы. Киев: Наукова Думка, 1976. 249 с.

16. Васильев И.Б., Колев Ю.И., Кузнецов П.Ф. Новые материалы бронзового века с территории Северного Прикаспия // Древние культуры Северного Прикаспия. Куйбышев: КГПИ, 1986. С. 108-149.

17. Кузнецов П.Ф., Мочалов О.Д. Особый тип керамики как отражение культурных связей в начале среднего бронзового века Волго-Уралья // Известия Самарского научного центра РАН. Т. 11. № 6. Самара, 2009. C. 292-295.

18. Гей А.Н. Новотиторовская культура. М.: ТОО «Старый сад», 2000. 224 с.

19. Мочалов О.Д. Керамика погребальных памятников эпохи бронзы лесостепи Волго-Уральского междуречья. Самара: СамГПУ, 2008. 252 с.

20. Лагодовська Р.Ф., Шапошникова О.Г., Макаревич М.Л. Михайлівське поселення. Киів: АН УССР, 1962. $247 \mathrm{c}$.

21. Коробкова Г.Ф., Шапошникова О.Г. Поселение Михайловка - эталонный памятник древнеямной культуры (экология, жилища, орудия труда, системы жизнеобеспечения, производственная структура). СПб.: Европейский дом, 2005. 326 с.

22. Тесленко Д.Л. О находках реповидной керамики в погребениях эпохи ранней бронзы Поднепровья // Взаимодействие и развитие древних культур южного пограничья Европы и Азии: материалы конференции. Саратов: Мин-во культуры Саратовской области, 2000. C. $45-47$.

Работа выполнена при поддержске гранта РГНФ № 14-01-00127 и госзадания Министерства образования и науки РФ № 33.1471.2014.

\section{LARGE TARE VESSELS OF THE BRONZE AGE TURGANIC SETTLEMENT IN ORENBURG REGION}

(C) 2016

N.P. Salugina, candidate of history sciences, associate professor of Theory and History of Culture Department Samara State Institute of Culture, Samara (Russia)

N.L. Morgunova, doctor of history sciences, professor, head of Archaeological Laboratory Orenburg State Pedagogical University, Orenburg (Russia)

M.A. Turetskii, candidate of history sciences, senior researcher

Volga Region branch of Institute of Russian History of Russian Academy of Sciences, Samara (Russia)

Abstract. In the ceramic collection of Turganic settlement in the Orenburg region there is a group of bronze age pottery, which by its morphological and technological indicators stands out sharply from the main group of dishes. They are large size vessels with massive aureoles and distended body. The authors called these vessels «hums». The aim of this study is to identify cultural-chronological position of the specified group of dishes in the system of the antiquities 
of the early - middle bronze age. Within this group the authors distinguish two types. The basis for type selection was the particular design of the upper part of the vessel. The first type is ceramics from Turganic settlement and the vessel from the burial mound Perevolotsky I. Morphological and technological features, and a series of radiocarbon dates has allowed to date these vessels to the time of the yamnaya culture formation in the Volga-Ural region (Repinsky stage). The authors suggest that the appearance of such vessels should be an imitation of the Maikop pottery. It could be penetration of small groups of craftsmen or the intensification of contacts with the population of the North Caucasus. The second type of pottery from Turganic settlement is similar to the burial mound Kardailovsky I (mound 1, burial 3) in Orenburg region, in the Northern pre-Caspian, region of the Samara river, Kuban and the Dnieper. Researchers have noted the scarcity and originality of this dish. The chronological and cultural position of such vessels is determined within the III Millennium BC (calibrated values).

Keywords: early and middle bronze age; ceramic type hums; turnip type vessels; radiocarbon chronology; cultural affiliation; yamnaya; Maikopsko-Novosvobodnaya; katakombnaya culture; ornaments; technology of ceramics production; raw material; molding material; clay; silty clay; grog; crushed shell.

УДК 94 (367) : $929.5 « 13 »$

\section{СЕДЬМАЯ СТЕПЕНЬ РОДСТВА ВО ВНУТРИДИНАСТИЧЕСКИХ БРАКАХ РЮРИКОВИЧЕЙ В ХІІ ВЕКЕ}

(C) 2016

С.Н. Абуков, кандидат исторических наук, старший преподаватель

кафедры историографии, источниковедения, археологии и методики преподавания истории Донецкий национальный университет, Донеик (Донеикая Народная Республика)

Аннотащия. Вопрос политической ситуации на Руси в XII в. невозможно рассматривать в отрыве от междукняжеских отношений Рюриковичей. Их составляющей были внутридинастические браки древнерусских князей, игравшие очень важную роль в политических отношениях того периода. Однако существовали церковные запреты, которые ограничивали возможности таких матримониальных союзов. Историки дискутируют о разрешенной в подобных случаях степени заключения браков. Данная статья посвящена месту 7-й степени родства во внутридинастических браках Рюриковичей в ХІІ в. Автор исследовал известные примеры брачных союзов между различными линиями потомков Ярослава Мудрого и пришел к выводу, что именно такая степень родства была изначально признана допустимой для древнерусских князей. В начале века она связала с другими князьями членов семьи Владимира Мономаха, но была продолжена и среди потомков как Мономаха, так и Олега Черниговского. Во второй половине XII в. имели место внутридинастические браки древнерусских князей и 6-й степени родства, однако такая практика была скорее исключением. 7-я степень родства оставалась самой близкой для Рюриковичей и в дальнейшем.

Ключевые слова: князь; Киевская Русь; Рюриковичи; брак; родственные связи; ХІІ век; степень родства; Владимир Мономах; Мономашичи; Ольговичи; Роман Владимирович; Рюрик Ростиславич; Всеволодко Городенский; Ярослав Святолчич; Всеволод Ольгович; Глеб Святославич; Давыд Ольгович.

Изучение внутридинастических браков древнерусских князей еще не получило комплексного исследования, при том, что без них невозможно представить не только междукняжеские отношения Рюриковичей, но и политическую историю Руси в целом. Брачные союзы князей - важнейший индикатор политических отношений среди правящей элиты, в период феодальной раздробленности представлявшей правителей крупных государственных образований. Заключение подобных браков не было спонтанным, имело свои традиции и ограничения.

В первую очередь речь идет о разрешенной степени родства между женихом и невестой. Изучение данной проблемы позволяет более глубоко понять особенности политического взаимодействия Рюриковичей, их матримониальные отношения с их ограничениями, психологию элит и пр. Практически все труды крупнейших историков, исследовавших историю Руси в разные периоды, как и специальные работы генеалогов, касались браков древнерусских князей в целом, не акцентируя внимания на таком вопросе, как степени родства. С начала XXI в. ведущими исследованиями по Рюриковичам являются работы Л.В. Войтовича [1]. Только в последнее время проблема внутридинастических браков древнерусских князей приобрела актуальность среди ученых. Особый интерес вызывает у специалистов именно близкородственные браки потомков Рюрика, о чем говорит серия работ вышедших в последние годы, хотя исследователи и не пришли к единому мнению по данной проблематике $[2 ; 3 ; 4 ; 5 ; 6]$.

Согласно византийским церковным канонам, принятым и на Руси, действовали запреты на близкородственные браки. Допустимой для брака между женихом и невестой считалась 8-я степень родства. При этом с оговорками возможным был брак и в 7-й степени родства [7]. Рассмотрим первые известные примеры браков в этой степени родства среди русских князей в XII в.

Итак, с конца XI в. Рюриковичи стали вступать в браки между собой. Первый достоверный пример брака между двумя линиями потомков Владимира Святославича: Изяславичами и Ярославичами - брак, заключенный в 8-й степени родства (рис. 1) [8, стб. 492].

В начале XII в. внутридинастическая брачная активность Рюриковичей выходит на новый уровень. Это были уже сами Ярославичи. Что касается предполагаемого Л.Е. Махновцом [9, с. 153] более раннего брака между Давыдом Игоревичем и дочерью Рости- 